\title{
Níveis de metionina + cistina digestível para poedeiras leves no período de 42 a 58 semanas de idade
}

\author{
Gladstone Brumano ${ }^{1}$, Paulo Cezar Gomes ${ }^{2}$, Juarez Lopes Donzele ${ }^{2}$, Horacio Santiago \\ Rostagno $^{2}$, Tatiana Cristina da Rocha ${ }^{1}$, Heloisa Helena de Carvalho Mello ${ }^{1}$
}

\footnotetext{
1 Programa de Pós-graduação da Universidade Federal de Viçosa.

2 Departamento de Zootecnia da Universidade Federal de Viçosa.
}

RESUMO - Com o objetivo de determinar os níveis de aminoácidos sulfurosos digestíveis para estabelecer a relação ideal metionina + cistina/lisina em rações para poedeiras leves no período de 42 a 58 semanas de idade, 216 aves da marca comercial Hy-Line W36 foram distribuídas em delineamento de blocos casualizados com seis dietas, seis repetições e seis aves por unidade experimental. O nível de lisina utilizado na dieta experimental foi de $0,770 \%$ para consumo médio esperado de $731 \mathrm{mg} / \mathrm{ave} / \mathrm{dia}$ de lisina e de 95 g/ave/dia de ração. Os níveis de aminoácidos sulfurosos digestíveis foram obtidos a partir de uma dieta basal deficiente em metionina + cistina digestível (0,65\%), suplementada com 0,00;0,05;0,10;0,15;0,20 e 0,25\% de DL-metionina (99,2\%), de forma a proporcionar relações metionina + cistina/lisina de 84, 91, 97, 104, 110 e $117 \%$. O período experimental teve duração de 16 semanas e foi subdividido em quatro ciclos de coleta dos ovos, cada um de 28 dias. Houve efeito quadrático dos níveis de $0,826 \%$ e $0,775 \%$ de metionina + cistina digestível sobre a produção de ovos e a eficiência de utilização de lisina por produção total de ovos, respectivamente. O nível de metionina + cistina digestível considerado exigência para poedeiras leves no período de 42 a 58 semanas de idade foi de 0,775\%, que corresponde a consumo de $708 \mathrm{mg} / \mathrm{ave} / \mathrm{dia}$ de metionina + cistina digestível e relação metionina + cistina/lisina de 101\%.

Palavras-chave: aminoácidos essenciais, exigências nutricionais, galinhas, proteína ideal

\section{Digestible methionine + cystine levels for light-weight laying hens from 42 to 58 weeks of age}

\begin{abstract}
Aiming at determining levels of digestible sulfurous amino acids to establish the ideal methionine + cystine/lysine relationship in rations for light-weight laying hens in the period from 42 to 58 weeks of age, 216 birds of the commercial brand Hy- Line W36 were distributed in a randomized block design with 6 diets, 6 repetitions and 6 birds per experimental unit. The level of digestible lysine used in the experimental diet was $0.770 \%$ for an expected average consumption of $731 \mathrm{mg} / \mathrm{hen} /$ day of lysine and $95 \mathrm{~g} / \mathrm{hen} /$ day of ration. Levels of digestible sulfurous amino acids were obtained from a basal diet deficient in digestible methionine + cystine (0.65\%), supplemented with $0.00 ; 0.05,0.10,0.15$, 0.20 and $0.25 \%$ of DL-methionine (99.2\%), so to provide a methionine + cystine/lysine relationship of $84,91,97,104$, 110 and $117 \%$. The experimental period lasted for 16 weeks and it was subdivided in 4 cycles of egg collection, each one corresponding to 28 days. There was a quadratic effect of the digestible methionine + cistine levels of $0.826 \%$ and $0.775 \%$ on the egg production and lysine utilization efficiency for total egg production, respectively. The digestible methionine + cystine level considered as a requirement for light-weight laying hens in the period from 42 to 58 weeks of age were $0.775 \%$, corresponding to digestible methionine + cystine consumption of $708 \mathrm{mg} / \mathrm{hen} / \mathrm{day}$, and a methionine + cystine/ lysine relationship of $101 \%$.
\end{abstract}

Key Words: essential amino acids, hens, ideal protein, nutritional requirements

\section{Introdução}

As poedeiras comerciais passam por constantes avanços genéticos, tornando-se cada vez mais precoces e apresentando altos picos de produção, o que indica que suas necessidades nutricionais devem ser periodicamente revistas, para garantir o máximo desempenho produtivo.
As exigências em proteína e em aminoácidos de poedeiras podem variar conforme o peso corporal, a taxa de crescimento e a produção de ovos, sendo importante que os nutricionistas atentem para esses pontos ao formular as rações.

Entre os diversos nutrientes presentes nas dietas de aves, a proteína é considerada um dos principais, devido ao 
elevado custo, sendo importante no desempenho dos animais. Segundo Dale (1994), a proteína dietética influência no desempenho dos animais e sua eficiência de utilização é dependente da quantidade, da composição e da digestibilidade de seus aminoácidos.

Os aminoácidos são importantes para o desempenho produtivo das poedeiras, pois têm relação direta com a produção de ovos, conversão alimentar e eficiência na utilização do nitrogênio. Os aminoácidos são componentes essenciais dos ovos e constituem as moléculas proteicas presentes no albúmen e na gema (Leeson \& Summers, 2001), além de serem importantes para o desenvolvimento e a manutenção corporal das aves. A metionina é um aminoácido de importante controle no peso do ovo, pois a poedeira consome energia para sustentar o número de ovos, mas o peso dos ovos depende dos níveis de aminoácidos da dieta (Harms, 1999). A metionina é o primeiro aminoácido limitante em rações a base de milho e farelo de soja, sendo que sua deficiência é corrigida pela suplementação de metionina sintética.

Objetivou-se neste experimento avaliar níveis de metionina + cistina digestíveis para estabelecer a relação ideal metionina + cistina/lisina em rações para poedeiras comerciais leves no período de 42 a 58 semanas de idade.

\section{Material e Métodos}

O experimento foi conduzido nas instalações da Seção de Avicultura do Departamento de Zootecnia da Universidade Federal de Viçosa (UFV) no período de 6 de julho a 26 de outubro de 2006.

Utilizaram-se 216 aves da marca comercial Hy-line W-36, no período de 42 a 58 semanas de idade, em um delineamento em blocos casualizados com seis dietas, seis repetições e seis aves por unidade experimental.

As poedeiras foram adquiridas ao completarem 40 semanas de idade e manejadas conforme descrito no manual da linhagem, porém seguindo as recomendações de Rostagno et al. (2005) na elaboração das dietas. As aves foram alojadas em um galpão de postura totalmente aberto nas laterais e coberto com telhas de barro, sendo alojadas aos pares, em gaiolas de 25x40x45 cm.

O programa de luz adotado foi o de 17 horas de luz diária. O controle do fornecimento de luz foi realizado por meio de um relógio automático (timer), que permitiu o acender e o apagar das luzes durante o período da noite e da madrugada.

O controle de produção de ovos foi realizado no período de 40 a 42 semanas de idade, de modo a permitir a uniformização do índice de postura das aves. Em seguida, foi realizada a distribuição das poedeiras, padronizando-as por peso corporal e porcentagem de postura, antes da administração das dietas experimentais.

Às 42 semanas de idade, as aves foram submetidas às dietas, que consistiam de rações isonutritivas (Tabela 1), exceto para os níveis de metionina + cistina digestível, que variaram em seis níveis, obedecendo às relações metionina + cistina/lisina de 84, 91, 97, 104, 110 e 117. Tais relações resultaram em níveis obtidos a partir de uma dieta basal (Tabela 1) deficiente em metionina + cistina digestível $(0,65 \%)$, suplementada com 0,$00 ; 0,05 ; 0,10 ; 0,15 ; 0,20$ e 0,25\% de DL-metionina (99,2\%). O nível subótimo de lisina utilizado na dieta experimental foi de $0,770 \%$ para um consumo médio esperado de $731 \mathrm{mg} /$ ave/dia de lisina e de 95 g/ave/dia de ração.

As suplementações com DL-metionina foram feitas em substituição ao aminoácido L-glutâmico em equivalente proteico. Os demais nutrientes contidos nas rações, exceto as relações dos aminoácidos em relação à lisina, foram segundo as recomendações preconizadas por Rostagno et al. (2005).

As rações foram fornecidas, diariamente, em dois horários, às 7 e às 17 h, com consumo de água à vontade, durante todo o período experimental.

As temperaturas no galpão foram monitoradas uma vez ao dia, às $8 \mathrm{~h}$, por meio de três termômetros de máxima e mínima, que estavam distribuídos em pontos distintos por todo o galpão, posicionados à altura das aves. As temperaturas ambiente mínima e máxima variaram de $8^{\circ} \mathrm{C}$ a $19^{\circ} \mathrm{C}$ e de $23^{\circ} \mathrm{C}$ a $29^{\circ} \mathrm{C}$, respectivamente, durante o período experimental.

O período experimental teve duração de 16 semanas e foi subdividido em quatro ciclos de coleta dos ovos, cada um correspondente a 28 dias, para avaliação dos seguintes parâmetros:

- Consumo alimentar: foi determinado o consumo de ração, de metionina + cistina e de lisina ao término de cada período de 28 dias, por meio da divisão da quantidade de ração (g), de metionina + cistina (mg) e de lisina (mg) consumida, respectivamente, em cada unidade experimental, pelo número de aves das unidades experimentais por dia.

- Produção de ovos: foi computada diariamente e de acordo com o número de aves alojadas por unidade experimental.

- Eficiência de utilização de lisina por produção total de ovos: foi calculado pela divisão do consumo de lisina/ave em gramas dos quatro ciclos, pela produção total de ovos/ ave dos quatro ciclos, em cada unidade experimental.

- Conversão alimentar: foi calculada pela divisão do consumo de ração pela produção em dúzias de ovos 
Tabela 1 - Composição das dietas experimentais

\begin{tabular}{|c|c|c|c|c|c|c|}
\hline & \multicolumn{6}{|c|}{ Nível de metionina + cistina (\%) } \\
\hline & 0,00 & 0,05 & 0,10 & 0,15 & 0,20 & 0,25 \\
\hline \multicolumn{7}{|l|}{ Ingrediente } \\
\hline Farelo de soja $(45,32 \%$ de $\mathrm{PB})$ & 21,501 & 21,501 & 21,501 & 21,501 & 21,501 & 21,501 \\
\hline Farelo de glúten $60 \%$ & 2,500 & 2,500 & 2,500 & 2,500 & 2,500 & 2,500 \\
\hline Óleo de soja & 2,987 & 2,987 & 2,987 & 2,987 & 2,987 & 2,987 \\
\hline Sal & 0,528 & 0,528 & 0,528 & 0,528 & 0,528 & 0,528 \\
\hline Mistura vitamínica ${ }^{1}$ & 0,100 & 0,100 & 0,100 & 0,100 & 0,100 & 0,100 \\
\hline Mistura mineral $^{2}$ & 0,050 & 0,050 & 0,050 & 0,050 & 0,050 & 0,050 \\
\hline Butil-hidroxi-tolueno (antioxidante) & 0,010 & 0,010 & 0,010 & 0,010 & 0,010 & 0,010 \\
\hline Cloreto de colina $60 \%$ & 0,020 & 0,020 & 0,020 & 0,020 & 0,020 & 0,020 \\
\hline Cloreto de potássio & 0,079 & 0,079 & 0,079 & 0,079 & 0,079 & 0,079 \\
\hline L-triptofano (98\%) & 0,045 & 0,045 & 0,045 & 0,045 & 0,045 & 0,045 \\
\hline \multicolumn{7}{|l|}{ Nutriente (composição calculada) } \\
\hline Proteína bruta & 16,30 & 16,30 & 16,30 & 16,30 & 16,31 & 16,31 \\
\hline Energia metabolizável & 2.900 & 2.901 & 2.902 & 2.903 & 2.904 & 2.905 \\
\hline Metionina + cistina digestível & 0,650 & 0,700 & 0,750 & 0,800 & 0,850 & 0,900 \\
\hline Metionina digestível & 0,410 & 0,460 & 0,510 & 0,560 & 0,610 & 0,660 \\
\hline Lisina digestível & 0,770 & 0,770 & 0,770 & 0,770 & 0,770 & 0,770 \\
\hline Treonina digestível & 0,578 & 0,578 & 0,578 & 0,578 & 0,578 & 0,578 \\
\hline Tryptofano digestível & 0,208 & 0,208 & 0,208 & 0,208 & 0,208 & 0,208 \\
\hline Isoleucina digestível & 0,663 & 0,663 & 0,663 & 0,663 & 0,663 & 0,663 \\
\hline Valina digestível & 0,693 & 0,693 & 0,693 & 0,693 & 0,693 & 0,693 \\
\hline
\end{tabular}

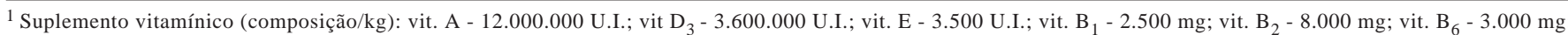
ácido pantotênico - 12.000 mg; biotina - 200 mg; vit. K - 3.000 mg; ácido fólico - 3.500 mg; ácido nicotínico - 40.000 mg; vit. B 12 - 20.000 mcg; selênio - 130 mg; veículo q.s.p. - 1.000 g.

${ }^{2}$ Suplemento mineral (composição/kg): manganês - 160 g, ferro - 100 g; zinco - 100 g; cobre - 20 g; cobalto - 2 g; iodo - 2 g; excipiente q.s.p. - 1.000 g.

3 Butil-hidróxi-tolueno.

( kg/dúzia) e pela massa de ovos ( $\mathrm{kg} / \mathrm{kg})$, em cada um dos quatro ciclos.

- Peso médio dos ovos: foram utilizados todos os ovos íntegros coletados nos três últimos dias de cada um dos quatro ciclos de 28 dias. A média do peso dos ovos foi obtida pela divisão do peso total dos ovos coletados pelo número de ovos coletados, por unidade experimental e expressos em gramas.

- Massa de ovos: foi expressa em gramas de ovos por ave por dia (g/ave/dia), multiplicando o peso médio dos ovos no ciclo pelo número total de ovos produzidos no respectivo ciclo, dividido pelo número total de aves dos dias relativos a esse período.

- Ovos não-comerciais: foram computados os ovos trincados, quebrados, de casca mole, sem casca, de duas gemas e sem gema. A relação de ovos perdidos e o total de ovos produzidos no experimento foram apresentados na forma de porcentagem para cada uma das dietas experimentais.

- Componentes dos ovos: foram coletados dois ovos por dia de cada repetição durante os três últimos dias a cada período de 28 dias. Obteve-se, primeiramente, o peso total do ovo e, em seguida, procedeu-se a sua quebra para a pesagem da gema e da casca. Para realizar a separação dos componentes dos ovos (gema, casca e albúmen), utilizou-se um separador de gemas convencional. As cascas foram lavadas, deixadas a secar e, na sequência, pesadas. O peso do albúmen foi obtido pela diferença entre o peso total do ovo menos o peso da casca e da gema. A gema, o albúmen e a casca foram determinados em porcentagem.

- Ganho de peso: todas as poedeiras de cada repetição foram pesadas no início e no final do período experimental, para obtenção do ganho de peso médio, mediante a diferença entre as duas pesagens. 
- Qualidade interna dos ovos: a qualidade interna dos ovos foi medida por uma amostra de todos os ovos de cada repetição, coletados nos três últimos dias de cada um dos quatro ciclos de 28 dias. Os ovos, identificados com o número de cada dieta experimental e repetição, foram coletados e pesados em balança com precisão de $0,1 \mathrm{~g}$. No mesmo dia, procedeu-se à quebra destes, para a medição da altura de gema e de albúmen, feita com micrômetro do tipo AMES S-6428, seguindo-se a metodologia descrita por Snyder (1961), para, posteriormente, determinar as unidades Haugh, segundo o critério desenvolvido por Haugh (1937). Também foram medidos os diâmetros de albúmen e de gema, com paquímetro, para determinação dos índices de albúmen e de gema.

O valor da exigência do aminoácido em estudo foi estimado por meio das variáveis estudadas, mediante o uso de modelos quadrático ou LRP (Linear Response Plateau), conforme ajustamento dos dados, utilizando o programa SAEG - Sistema para Análises Estatísticas e Genéticas (UFV, 2005).

\section{Resultados e Discussão}

Foi verificado efeito $(\mathrm{P}<0,01)$ dos níveis de metionina + cistina sobre as variáveis consumo de ração, de metionina + cistina digestível e de lisina digestível, que aumentaram de forma linear (Tabelas 2 e 3). O consumo médio de ração das poedeiras $(91,2 \mathrm{~g})$ foi abaixo do esperado e do sugerido pelo manual da linhagem Hy-line W36 (95 g). O consumo de ração pode ter sofrido influência da temperatura ambiente, que variou durante o período estudado, chegando a temperaturas máximas de $29^{\circ} \mathrm{C}$ no interior do galpão, podendo, dessa forma, ter reduzido a ingestão de alimento ao longo do dia.
Os resultados estatísticos para consumo de lisina seguiram os resultados encontrados para consumo de ração, pois esse aminoácido encontrava-se proporcionalmente igual entre as dietas experimentais. O consumo de metionina + cistina digestível aumentou linearmente devido à concentração desses aminoácidos na dieta.

Efeito estatístico similar a esse estudo foi observado por Cupertino et al. (2009), que verificaram efeito linear para consumo de ração com níveis de 0,492 a 0,700\% de metionina + cistina digestível para poedeiras semipesadas de 54 a 70 semanas. Porém, testando os mesmos níveis, no mesmo período, com poedeiras leves, não constataram diferença significativa para consumo de ração. Por outro lado, Barbosa et al. (1999) constataram efeito quadrático com dietas variando os níveis de metionina + cistina de 0,484 a 0,734\% para poedeiras leves de segundo ciclo.

Houve efeito quadrático $(\mathrm{P}<0,05)$ dos níveis de metionina + cistina digestível sobre a produção de ovos e a eficiência de utilização de lisina por produção total de ovos ao nível de $0,833 \%$ e de $0,775 \%$ de metionina + cistina digestível, respectivamente, que correspondem a consumos de aminoácidos sulfurosos digestíveis de 771 e de $708 \mathrm{mg} /$ ave/dia e relações metionina + cistina/lisina de $108 \%$ e de $101 \%$.

Embora tenha verificado efeito quadrático para o parâmetro produção de ovos, o modelo LRP foi o que apresentou menor soma dos quadrados dos desvios e que melhor se ajustou aos dados, obtendo um platô ao nível de 0,761\%, que corresponde a $693 \mathrm{mg} /$ ave/dia de consumo de metionina + cistina digestível e 99\% de relação metionina + cistina com a lisina. As relações de metionina + cistina com a lisina encontradas para as variáveis produção de ovos e a eficiência de utilização de lisina por produção total de ovos são superiores às recomendadas por Rostagno et al. (2005)

Tabela 2 - Efeito dos níveis de metionina + cistina digestível $(\mathrm{M}+\mathrm{C})$ para poedeiras leves no período de 42 a 58 semanas de idade

\begin{tabular}{|c|c|c|c|c|c|c|c|c|c|}
\hline $\begin{array}{l}\text { Dieta } \\
(\% \mathrm{M}+\mathrm{C})\end{array}$ & $\begin{array}{l}\text { Consumo } \\
\text { de ração } \\
\text { (g/ave/dia) }\end{array}$ & $\begin{array}{c}\text { Consumo } \\
\text { de } \mathrm{M}+\mathrm{C}^{1} \\
\text { (mg/ave/dia) }\end{array}$ & $\begin{array}{c}\text { Consumo } \\
\text { de lisina }{ }^{1} \\
\text { (mg/ave/dia) }\end{array}$ & $\begin{array}{c}\text { Produção } \\
\text { de ovos }{ }^{2} \\
(\%)\end{array}$ & $\begin{array}{l}\text { Eficiência lisina/ } \\
\text { total de ovos }{ }^{2} \\
\text { (g/ave/total ovos) }\end{array}$ & $\begin{array}{c}\text { Peso } \\
\text { de ovo }{ }^{1} \\
(\mathrm{~g})\end{array}$ & $\begin{array}{c}\text { Massa } \\
\text { de ovos } \\
\text { (g/ave/dia) }\end{array}$ & $\begin{array}{l}\text { Conversão dúzia } \\
\text { de ovos }{ }^{4} \\
\text { (kg/dúzia) }\end{array}$ & $\begin{array}{c}\text { Conversão } \\
\text { massa de } \\
\operatorname{ovos}^{4}(\mathrm{~kg} / \mathrm{kg})\end{array}$ \\
\hline 0,650 & 89,35 & 580,8 & 688,0 & 80,75 & 0,852 & 58,32 & 47,11 & 1,329 & 1,899 \\
\hline 0,700 & 88,55 & 619,9 & 681,9 & 82,55 & 0,826 & 60,00 & 49,54 & 1,289 & 1,790 \\
\hline 0,750 & 90,05 & 675,3 & 693,4 & 85,29 & 0,813 & 60,01 & 51,23 & 1,268 & 1,763 \\
\hline 0,800 & 91,88 & 735,1 & 707,5 & 87,13 & 0,813 & 60,93 & 54,24 & 1,239 & 1,694 \\
\hline 0,850 & 93,12 & 791,6 & 717,1 & 85,07 & 0,843 & 62,98 & 53,66 & 1,314 & 1,738 \\
\hline 0,900 & 93,94 & 845,5 & 723,3 & 85,90 & 0,842 & 63,93 & 55,10 & 1,310 & 1,706 \\
\hline Média & 91,15 & 708,0 & 701,9 & 84,45 & 0,832 & 61,03 & 51,81 & 1,292 & 1,765 \\
\hline $\mathrm{CV}^{5}(\%)$ & 2,34 & 2,48 & 2,34 & 3,73 & 4,66 & 2,17 & 3,84 & 4,07 & 3,59 \\
\hline
\end{tabular}

${ }^{1}$ Efeito linear $(\mathrm{P}<0,01)$ pelo teste $\mathrm{F}$.

2 Efeito quadrático $(\mathrm{P}<0,05)$ pelo teste $\mathrm{F}$.

${ }^{3}$ Efeito quadrático $(\mathrm{P}<0,07)$ pelo teste $\mathrm{F}$.

${ }^{4}$ Efeito quadrático (P 0,01) pelo teste $\mathrm{F}$.

5 Coeficiente de variação. 
Tabela 3 - Estimativas dos níveis de metionina + cistina digestível (M+C) para poedeiras leves no período de 42 a 58 semanas de idade

\begin{tabular}{|c|c|c|c|c|c|c|}
\hline Modelo & Equação de regressão & Plateau & Pmáx/Pmín & Exigência (\%) & $\mathrm{R}^{2}$ & SQD \\
\hline \multicolumn{7}{|l|}{ Linear } \\
\hline Consumo de ração & $\hat{Y}=74,0906+22,0115 x$ & - & - & $\geq 0,900$ & 0,90 & 2,2392 \\
\hline Consumo de lisina & $\hat{Y}=0,570497+0,169489 x$ & - & - & $\geq 0,900$ & 0,90 & 0,0001 \\
\hline Consumo de $\mathrm{M}+\mathrm{C}$ & $\hat{Y}=-0,132677+1,08476 x$ & - & - & $\geq 0,900$ & 1,00 & 0,0001 \\
\hline Peso de ovo & $\hat{Y}=44,2401+21,6641 x$ & - & - & $\geq 0,900$ & 0,95 & 1,1439 \\
\hline \multicolumn{7}{|l|}{ Quadrático } \\
\hline Produção de ovos & $\hat{Y}=-33,0798+286,425 x-171,819 x^{2}$ & - & 86,29 & 0,833 & 0,89 & 3,1413 \\
\hline ELP & $\hat{Y}=2,11241-3,34639 x+2,15908 x^{2}$ & - & 0,815 & 0,775 & 0,78 & 0,0003 \\
\hline Massa ovos & $\hat{Y}=-32,2375+187,202 x-100,394 x^{2}$ & - & 55,03 & 0,932 & 0,96 & 1,6811 \\
\hline Conversão alimentar / dúzia de ovos & $\hat{Y}=3,70003-6,26212 x+4,02146 x^{2}$ & - & 1,262 & 0,778 & 0,78 & 0,0017 \\
\hline Conversão alimentar / massa de ovos & $\hat{Y}=5,12779-8,09084 x+4,78288 x^{2}$ & - & 1,706 & 0,846 & 0,92 & 0,0022 \\
\hline \multicolumn{7}{|l|}{ LRP } \\
\hline Produção de ovos & $\hat{Y}=43,7824+52,1864 x$ & 85,49 & - & 0,761 & 0,99 & 0,5198 \\
\hline Peso de ovo & $\hat{Y}=45,0899+20,4783 x$ & 63,46 & - & 0,897 & 0,91 & 1,5195 \\
\hline Conversão alimentar / dúzia de ovos & $\hat{Y}=1,7045-0,583644 x$ & 1,312 & - & 0,672 & 0,98 & 0,0031 \\
\hline Conversão alimentar / massa de ovos & $\hat{Y}=2,71544-1,28152 x$ & 1,722 & - & 0,775 & 0,95 & 0,0017 \\
\hline
\end{tabular}

ELP = eficiência de utilização de lisina por produção total de ovos.

e NRC (1994), que são de $91 \%$ e $84 \%$, respectivamente. No entanto, ao considerar o consumo diário de aminoácidos sulfurosos encontrado para a variável eficiência de utilização de lisina por produção total de ovos, verifica-se maior similaridade em relação ao consumo de $724 \mathrm{mg}$ proposto por Rostagno et al. (2005). Porém, o consumo médio de lisina digestível encontrado no presente estudo, de $702 \mathrm{mg} /$ ave/dia, foi inferior ao preconizado por Rostagno et al. (2005), de $796 \mathrm{mg} / \mathrm{ave} / \mathrm{dia}$. Isso sugere que os níveis de lisina digestível utilizados por esses autores em função da relação entre aminoácidos podem estar superestimados. Os altos índices produtivos (84,5\% de postura) alcançados nesse trabalho reforçam ainda mais tal hipótese. O manual da linhagem Hy-line W36 preconiza produção média de ovos de $86 \%$ em condições ótimas de manejo e recomenda um consumo médio de 729 mg/ave/dia de lisina digestível no período de 42 a 58 semanas de idade. Da mesma forma, baixa relação aminoácidos sulfurosos/ lisina foi recomendada no manual da linhagem Hy-line W36, que estabelece uma relação metionina + cistina com a lisina de $78 \%$.

Sá et al. (2007) identificaram resposta na produção de ovos de poedeiras quando suplementaram dietas com diversos níveis de aminoácidos sulfurosos. Estimaram como exigências, para poedeiras leves e semipesadas de 34 a 50 semanas de idade, consumos de 825 e de $793 \mathrm{mg} /$ ave/dia e relação metionina + cistina/lisina de 101\%. Relação aminoácidos sulfurosos com a lisina similar foi verificada por Bregendahl et al. (2008), que foi de 99\%, para máxima produção de ovos, com poedeiras leves, no período de 28 a 34 semanas de idade.

Outros autores (Bertran et al., 1995; NarvaezSolarte, 1996; Rodrigues et al., 1996; Novak et al., 2004;
Novak et al., 2006) também constataram resposta na porcentagem de postura de galinhas poedeiras ao forneceram dietas com diferentes níveis de aminoácidos sulfurosos.

Devido à variação no consumo de ração e, consequentemente, no consumo dos demais aminoácidos, sobretudo a lisina, aminoácido de grande importância na produção de ovos, tornou-se necessário, para definir a relação ideal metionina + cistina/lisina digestível, o parâmetro eficiência de utilização de lisina por produção total de ovos. Foi considerado o melhor tratamento aquele que apresentar menor valor desse parâmetro. O melhor valor de eficiência de utilização de lisina por produção total de ovos não significa que a lisina proporcionou tal ganho, mas que a relação de metionina + cistina/lisina digestível desse tratamento é a mais ajustada, pois os sulfurosos são os únicos aminoácidos com relações diferentes entre as dietas experimentais. Ao comparar os consumos médio de lisina ocorridos nos níveis de $0,80 \%$ e de $0,85 \%$ de metionina + cistina digestível, que foram de 707,5 e de $717,1 \mathrm{mg} / \mathrm{ave} / \mathrm{dia}$, respectivamente, e suas respectivas produções de ovos, de $87,13 \%$ e de $85,07 \%$, verifica-se que, apesar do maior consumo de lisina digestível do nível 0,85\% e de metionina + cistina digestível, que foi de 791,6 mg/ave/dia, o nível de $0,80 \%$, que apresentou consumo de 735,1 mg/ave/dia de metionina + cistina digestível, apresentou maior porcentagem de postura e melhor valor de eficiência de utilização de lisina por produção total de ovos. Esses dados sugerem que a relação entre os aminoácidos sulfurosos com a lisina foi mais ajustada no nível de 0,80\%.

Houve efeito linear crescente $(\mathrm{P}<0,01)$ para o peso dos ovos com o aumento dos níveis de aminoácidos. Porém, 
constatou-se um platô ao nível de 0,897\% de metionina + cistina digestível, que corresponde a um consumo de $840 \mathrm{mg} / \mathrm{ave} /$ dia desses aminoácidos, uma relação aminoácidos sulfurosos/lisina de 116 e um peso médio de ovo de 63,5 gramas. O manual da linhagem estudada sugere peso médio de ovo, para o período de 42 a 58 semanas de idade, de 62 gramas, com consumo de $558 \mathrm{mg} /$ ave/dia de metionina + cistina digestível e relação aminoácidos sulfurosos/lisina de 78\%. Segundo Hsu et al. (1998), há um incremento no tamanho dos ovos quando a ingestão de aminoácidos sulfurados é aumentada pelas aves. Sá et al. (2007) constataram aumento do peso dos ovos em razão do aumento do consumo de metionina + cistina digestível (593 a $836 \mathrm{mg} /$ ave/dia) para poedeiras no período de 34 a 50 semanas de idade. Cupertino et al. (2009) também verificaram aumento no peso dos ovos de forma proporcional ao consumo de aminoácidos sulfurosos de poedeiras semipesadas quando variou o consumo de metionina + cistina digestível de 521 a $784 \mathrm{mg} /$ ave/dia.

O peso médio dos ovos é reflexo do aumento no peso da gema e do albúmen, que variaram de 15,4 a 17,5 e de 37,8 a 41,4 g, respectivamente, e no aumento da porcentagem de gema, de modo proporcional ao consumo de metionina + cistina digestível pelas aves.

Constatou-se efeito $(\mathrm{P}<0,07)$ dos níveis de metionina + cistina sobre a massa de ovos, variando de forma quadrática, obtendo 0,932\% como nível ótimo, que corresponde a consumo de $878 \mathrm{mg} /$ ave/dia de metionina + cistina digestível, equivalendo a uma massa de ovos de $55 \mathrm{~g}$ de ovo/ave/dia e relação aminoácidos sulfurosos/lisina de $112 \%$.

A massa de ovos estipulada pelo manual da linhagem Hy-line W36 em condições ótimas de manejo, para o período de 42 a 58 semanas de idade, foi de $53 \mathrm{~g}$ de ovo/ave/dia, com consumos de 558 e de 720 mg/ave/dia de metionina + cistina e de lisina digestíveis, respectivamente.

Schutte et al. (1994) e Zollitsch et al. (1996) também obtiveram maior massa de ovos com o aumento no consumo de metionina + cistina. Cao et al. (1992) determinaram as exigências de metionina + cistina em 785 mg/ave/dia, para uma massa de ovos de 54,3 g de ovo/ave/dia. Cupertino et al. (2009) verificaram efeito quadrático para o parâmetro massa de ovos, ao trabalharem com poedeiras leves de 54 a 70 semanas de idade, em níveis de consumo de metionina + cistina que variaram de 536 a $784 \mathrm{mg} /$ ave/dia. No entanto, o consumo dos aminoácidos sulfurosos estimado por esses autores para máxima massa de ovos foi inferior (712 mg/ave/dia) ao verificado neste trabalho.

O aumento linear no consumo de ração não refletiu em efeito linear na conversão alimentar por dúzia, que apresentou resposta quadrática $(\mathrm{P}<0,01)$, obtendo melhora até o nível estimado de $0,778 \%$ de metionina + cistina digestível, equivalente a consumo de $711 \mathrm{~g} / \mathrm{ave} / \mathrm{dia}$ de aminoácidos sulfurosos e relação metionina + cistina com a lisina de 101\%. Da mesma forma, a conversão alimentar por massa de ovos apresentou efeito quadrático $(\mathrm{P}<0,01)$ aos níveis crescentes de metionina + cistina digestível da ração, alcançando um nível ótimo de $0,846 \%$ de metionina + cistina. No entanto, devido ao melhor ajuste dos dados e à menor soma dos quadrados dos desvios, optou-se pelo modelo LRP para a conversão por massa de ovos, que apresentou o nível ótimo de $0,775 \%$, correspondendo a consumo médio de $708 \mathrm{mg} /$ ave/dia de aminoácidos sulfurosos e relação metionina + cistina/lisina de 101\%.

A relação aminoácidos sulfurosos/lisina obtida nesse experimento foi similar à verificada por Sá et al. (2007), que foram de 97 e $99 \%$ para poedeiras leves e semipesadas de 34 a 50 semanas de idade, respectivamente, considerando a variável conversão alimentar ( $k g$ de ração/dúzia de ovos). Cupertino et al. (2009) constataram consumo de $685 \mathrm{mg} /$ ave/dia de metionina + cistina e relação aminoácidos sulfurosos/lisina de $105 \%$ para poedeiras leves de 54 a 70 semanas de idade, considerando o parâmetro conversão alimentar (kg de ração/kg de ovos), que apresentou efeito quadrático.

Foi verificado efeito linear crescente $(\mathrm{P}<0,05)$ para porcentagem de gema e linear decrescente $(\mathrm{P}<0,01)$ para porcentagem de casca com o aumento dos níveis de metionina + cistina digestível na ração (Tabelas 4 e 5).

Não houve efeito significativo $(\mathrm{P}>0,05)$ dos níveis de metionina + cistina digestível sobre a porcentagem de albúmen e de ovos não comerciais.

Uma provável explicação para o aumento na porcentagem de gema pode estar relacionada à formação da colina a partir de metionina, somada aos fosfolipídios para formar as lipoproteínas da gema. A quantidade de colina fornecida neste trabalho parece estar abaixo do exigido pelo animal, que, segundo Rostagno et al. (2005), a exigência em colina para poedeiras em produção seria de $20 \mathrm{mg}$ /ave/dia. Assim, um aumento na ingestão de metionina poderia proporcionar maior produção das lipoproteínas da gema, ocasionando aumento no percentual de gema.

De acordo com Novak et al. (2004), a síntese de proteína no tecido do magno pode ser afetada por mudanças na concentração de aminoácidos no sangue. Porém, o aumento da ingestão de metionina + cistina digestível no presente estudo não aumentou a porcentagem de albúmen $(\mathrm{P}>0,05)$, embora tenha aumentado o peso médio do albúmen, que variou de 35,4 a $38,5 \mathrm{~g}$ 
Tabela 4 - Efeito dos níveis de metionina + cistina digestível $(\mathrm{M}+\mathrm{C})$ para poedeiras leves no período de 42 a 58 semanas de idade

\begin{tabular}{|c|c|c|c|c|c|c|c|c|c|c|}
\hline $\begin{array}{l}\text { Dieta } \\
(\% \mathrm{M}+\mathrm{C})\end{array}$ & $\begin{array}{c}\% \text { gema }^{1} \\
(\%)\end{array}$ & $\begin{array}{c}\% \text { casca }^{2} \\
(\%)\end{array}$ & $\begin{array}{c}\text { \% albúmen } \\
(\%)\end{array}$ & $\begin{array}{c}\% \text { ovos }(\%) \\
\text { não comerciais }\end{array}$ & $\begin{array}{l}\text { Índice } \\
\text { gema }^{3}\end{array}$ & $\begin{array}{c}\text { Índice } \\
\text { albúmen }{ }^{4}\end{array}$ & $\begin{array}{l}\text { Unidade } \\
\text { Haugh }^{4}\end{array}$ & $\begin{array}{c}\text { Peso inicial } \\
\text { (kg/ave) }\end{array}$ & $\begin{array}{c}\text { Peso final }{ }^{2} \\
\text { (kg/ave) }\end{array}$ & $\begin{array}{c}\text { Ganho de } \\
\operatorname{peso}^{2} \text { (g/ave) }\end{array}$ \\
\hline 0,650 & 26,20 & 9,33 & 64,48 & 0,59 & 0,463 & 0,126 & 93,51 & 1,429 & 1,454 & 25,0 \\
\hline 0,700 & 26,60 & 9,34 & 64,09 & 0,45 & 0,455 & 0,118 & 91,77 & 1,416 & 1,466 & 49,7 \\
\hline 0,750 & 26,84 & 9,13 & 64,02 & 0,38 & 0,452 & 0,114 & 90,43 & 1,406 & 1,450 & 44,0 \\
\hline 0,800 & 26,75 & 8,92 & 64,32 & 0,49 & 0,447 & 0,115 & 90,92 & 1,415 & 1,482 & 67,0 \\
\hline 0,850 & 27,06 & 8,85 & 64,09 & 0,67 & 0,449 & 0,111 & 89,72 & 1,441 & 1,529 & 88,5 \\
\hline 0,900 & 27,07 & 8,86 & 64,07 & 0,68 & 0,449 & 0,115 & 90,60 & 1,421 & 1,513 & 91,4 \\
\hline Média & 26,75 & 9,07 & 64,18 & 0,54 & 0,453 & 0,117 & 91,16 & 1,422 & 1,482 & 61,0 \\
\hline $\mathrm{CV}^{5}(\%)$ & 2,40 & 2,93 & 1,20 & 87,67 & 1,38 & 4,02 & 1,35 & 2,19 & 2,65 & 58,14 \\
\hline
\end{tabular}

${ }^{1}$ Efeito linear, $(\mathrm{P}<0,05)$, pelo teste $\mathrm{F}$.

2 Efeito linear, $(\mathrm{P}<0,01)$, pelo teste $\mathrm{F}$.

${ }^{3}$ Efeito quadrático, $(\mathrm{P}<0,05)$, pelo teste $\mathrm{F}$.

${ }^{4}$ Efeito quadrático, $(\mathrm{P}<0,01)$, pelo teste $\mathrm{F}$.

${ }^{5}$ Coeficiente de variação.

Tabela 5 - Estimativas dos níveis de metionina + cistina digestível (M+C) para poedeiras leves no período de 42 a 58 semanas de idade

\begin{tabular}{|c|c|c|c|c|c|c|}
\hline Modelo & Equação de regressão & Plateau & Pmáx/Pmín & Exigência (\%) & $\mathrm{R}^{2}$ & SQD \\
\hline \multicolumn{7}{|l|}{ Linear } \\
\hline$\%$ de gema & $\hat{Y}=24,2106+3,27584 x$ & - & - & $\geq 0,900$ & 0,86 & 0,0745 \\
\hline$\%$ de casca & $\hat{Y}=10,8315-2,26837 x$ & - & - & $\geq 0,900$ & 0,90 & 0,0259 \\
\hline Peso final & $\hat{Y}=1,25459+0,294017 x$ & - & - & $\geq 0,900$ & 0,73 & 0,0014 \\
\hline Ganho de peso & $\hat{Y}=-147,789+269,333 x$ & - & - & $\geq 0,900$ & 0,93 & 253,81 \\
\hline \multicolumn{7}{|l|}{ Quadrático } \\
\hline Unidade Haugh & $\hat{Y}=157,929-162,571 x+97,4184 x^{2}$ & - & 90,10 & 0,834 & 0,91 & 0,8157 \\
\hline Índice gema & $\hat{Y}=0,728859-0,666823 x+0,39536 x^{2}$ & - & 0,447 & 0,843 & 0,97 & 0,000005 \\
\hline Índice albúmen & $\hat{Y}=0,399976-0,693641 x+0,418159 x^{2}$ & - & 0,112 & 0,829 & 0,91 & 0,00001 \\
\hline \multicolumn{7}{|l|}{ LRP } \\
\hline Ganho de peso & $Y=-161,525+288,5 x$ & 91,4 & - & 0,877 & 0,90 & 232,382 \\
\hline
\end{tabular}

A redução na porcentagem de casca pode ser devido ao aumento verificado no tamanho dos ovos, sem aumento na produção da casca. Menor percentual de casca nos ovos poderia ocasionar cascas menos espessas, o que proporcionaria maior porcentagem de ovos não comerciais, devido a trincas e quebras nas cascas. No entanto, não houve reflexo significativo $(\mathrm{P}>0,05)$ dessa redução na porcentagem de casca do ovo sobre a incidência de ovos não comerciais.

Resultados semelhantes ao do presente estudo foram obtidos por Novak et al. (2004) ao trabalharem com poedeiras leves de 44 a 63 semanas de idade, com consumos de aminoácidos sulfurosos que variaram de 615 a 833 mg/ave/ dia, verificando efeito significativo para porcentagem de gema e não significativo para porcentagem de albúmen. Por outro lado, Pavan et al. (2005), trabalhando poedeiras semipesadas e consumos que variaram de 661 a $823 \mathrm{mg} / \mathrm{ave} /$ dia de aminoácidos sulfurosos, constataram efeito significativo tanto para percentual de gema quanto para percentual de albúmen.

Geraldo et al. (2006) também obteve resultados similares aos desse experimento, verificando aumento da porcentagem de gema e diminuição da porcentagem de casca ao variarem os níveis de aminoácidos sulfurosos de $0,578 \%$ a $0,810 \%$ para poedeiras leves no pico de produção. No entanto, Pavan et al. (2005) não constataram alteração no percentual da casca dos ovos quando variaram o consumo de aminoácidos sulfurosos para poedeiras.

Houve efeito dos níveis de metionina + cistina digestível sobre os parâmetros índice de gema $(\mathrm{P}<0,05)$, índice de albúmen $(\mathrm{P}<0,01)$ e unidade Haugh $(\mathrm{P}<0,01)$, apresentando resposta quadrática a tais parâmetros.

Houve influência do peso dos ovos sobre os parâmetros de qualidade interna dos ovos. Os melhores índices de gema, de albúmen e de unidade Haugh foram encontrados para os tratamentos que apresentaram menor peso de ovo, que são os de menores consumos de metionina + cistina digestível. Os consumos estabelecidos pelos modelos de regressão para os parâmetros de qualidade interna dos ovos variaram de 767 a $782 \mathrm{mg} /$ ave/dia de metionina + cistina digestível, com relações aminoácidos sulfurosos/ lisina variando de 108\% a 109\%.

O valor médio da unidade Haugh $(91,2)$ determinado nesse estudo foi superior ao apresentado pelo manual da linhagem $(85,2)$ para o mesmo período, ou seja, apresentou 
melhor qualidade interna de ovos, para um consumo médio maior de aminoácidos sulfurados digestíveis (708 vs. $558 \mathrm{mg} /$ ave/dia), menor consumo médio de lisina digestível (702 vs. 720 mg/ave/dia), similar valor médio de postura (84,5 vs. $86 \%$ ) e similar valor médio de peso de ovos (61 vs. $62 \mathrm{~g}$ ). Esses resultados demonstram que as relações metionina + cistina/lisina digestível encontradas nesse experimento, para os diversos parâmetros de qualidade estudados, que são superiores ao sugerido pelo manual, que foi de $78 \%$, mostram-se mais ajustadas para poedeiras leves no período de 42 a 58 semanas de idade.

Togashi et al. (2002) também verificaram efeito quadrático dos níveis de metionina + cistina estudados (540 a 780 mg/ave/dia de metionina + cistina digestível) sobre a unidade Haugh em poedeiras de 51 a 63 semanas de idade. Porém, Novak et al. (2004) não constataram efeito dos níveis de ingestão de aminoácidos sulfurosos (635 a $877 \mathrm{mg} /$ ave/dia) para poedeiras de 44 a 63 semanas de idade, sobre as unidades Haugh.

Os parâmetros de qualidade interna dos ovos (índice de gema e de albúmen e unidade Haugh) apresentam grandes variações de resultados para os diversos ensaios no qual foram analisados. O tempo de armazenamento dos ovos, a idade das aves, a temperatura ambiente, os tipos de aparelhos usados para determinar as medições, dentre outros fatores, afetam os resultados encontrados para essas variáveis.

Foi verificado efeito linear $(\mathrm{P}<0,01)$ dos níveis de metionina + cistina digestível sobre o peso final e o ganho de peso das aves, em que as aves ganharam em média 61 gramas durante o período experimental. Não houve efeito significativo $(\mathrm{P}>0,05)$ dos níveis de metionina + cistina digestível sobre o peso inicial. Verificou-se maior ganho corporal para os tratamentos de maior consumo de metionina + cistina digestível. As dietas experimentais de maior consumo de aminoácidos sulfurosos apresentaram também maiores consumos de ração e, consequentemente, de lisina, aminoácido este mais relacionado ao ganho de peso. As aves ganharam o dobro de peso em relação ao estabelecido pelo manual da linhagem Hy-line W36 (30 g) no período de 42 a 58 semanas de idade.

A mortalidade no período estudado foi de $0,92 \%$ distribuído entre as dietas, similar ao manual da linhagem Hy-line W36, que estabelece mortalidade de 1,10\% para o período de 42 a 58 semanas de idade. Apesar da influência dos aminoácidos metionina + cistina sobre o tamanho dos ovos, não foi constatado mortalidade das aves por prolapso.

\section{Conclusões}

O nível de metionina + cistina digestível considerado exigência para poedeiras leves de 42 a 58 semanas de idade, com base nos parâmetros estudados, é de 0,775\%, que corresponde a um consumo de $708 \mathrm{mg} /$ ave/dia de metionina + cistina digestível e relação metionina + cistina/lisina de 101\%.

\section{Referências}

BARBOSA, B.A.C.; SOARES, P.R.; ROSTAGNO, H.S. et al. Exigência nutricional de metionina + cistina para galinhas poedeiras de ovos brancos e marrons, no segundo ciclo de produção. Revista Brasileira Zootecnia, v.28, n.3, p.526-533, 1999.

BERTRAM, H.L.; DANNER, E.; JEROCH, K. et al. The influence of DL-methionine supplementation on the performance of laying hens under heat stress. Archive Geflügelk, v.59, p.314-318, 1995.

BREGENDAHL, K.; ROBERTS, S.A.; KERR, B. et al. Ideal rations of isoleucine, methionine, methionine plus cystine, threonine, tryptophan, and valine relative to lysine for white leghorntype laying hens of twenty-eight to thirty-four weeks of age. Poultry Science, v.87, p.744-758, 2008.

CAO, Z.; JEVNE, C.; COON, N. The methionine and methods of feeding on feed intake. Poulry Science, v.71 Suppl 1, p.39, 1992. (Abstr.).

CUPERTINO, E.S.; GOMES, P.C.; ALBINO, L.F.T. et al. Exigência nutricional de lisina digestível para galinhas poedeiras de 54 a 70 semanas de idade. Revista Brasileira de Zootecnia, v.38, n.3, p.480-487, 2009.

DALE, N. Proteína ideal para pollos de engorde. In: Avicultura Profesional, v.11, n.3, p.104-107, 1994.

GERALDO, A.; BERTECHINI, A.G.; CARVALHO, J.C.C. et al. Níveis de aminoácidos sulfurosos digestíveis e seus efeitos sobre o rendimento no processamento, qualidade interna e externa de ovos de poedeiras comerciais leves em pico de produção. In: REUNIÃO ANUAL DA SOCIEDADE DE ZOOTECNIA, 43. 2006, João Pessoa. Anais... João Pessoa: SBZ, 2006.

HARMS, R.H. Proteína (aminoácidos) para poedeiras. In: SIMPÓsIO INTERNACIONAL SOBRE NUTRIÇÃO DE AVES. 1999, Campinas. Anais... Campinas, 1999. p.111-122.

HAUGH, R.R. The Haugh Unit for measuring egg quality. United States Egg and Poultry Magazine, v.4, p.552, 1937.

HSU, J.C; LIN, C.Y.; CHIOU, P.W.S. Effects of ambient temperature and methionine supplementation of a low protein diet on the performance of laying hens. Animal Feed Science and Technology, v.74, p.289-299, 1998.

LEESON, S.; SUMMERS, J.D.; CASTON, L.J. Response of layers to low nutrient density diets. Journal applied Poultry Research, v.10, p.46-52. 2001.

NARVÁEZ-SOLARTE, W.V. Exigências em metionina + cistina para poedeiras leves e semipesadas. 1996. 57f. Dissertação (Mestrado em Zootecnia) - Universidade Federal de Viçosa, Viçosa, MG.

NATIONAL RESEARCH COUNCIL - NRC. Nutrient requiriments of poultry. 9.ed. Washington: National Academy of Sciences, 1994. 155p.

NOVAK, C.; YAKOUT, H.; SCHEIDELER, S. The combined effects of dietary lysine and total sulfur amino acid level on egg production parameters and egg components in Dekalb delta laying hens. Poultry Science, v.83, p.977-984, 2004.

NOVAK, C.; YAKOUT, H.; SCHEIDELER, S. The effect of dietary protein level and total sulfur amino acid:lysine ratio on egg production parameters and egg yield in Hy-Line W-98 hens. Poultry Science, v.85 (suppl.12), p.2195-2206, 2006. (Abstr.). 
PAVAN, A.C.; MÓRI, C.; GARCIA, E.A. et al. Níveis de proteína bruta e de aminoácidos sulfurados totais sobre o desempenho, a qualidade dos ovos e a excreção de nitrogênio de poedeiras de ovos marrons. Revista Brasileira de Zootecnia, v.34, n.2, p.568-574, 2005.

RODRIGUES, P.B.; BERTECHINI, A.G.; OLIVEIRA, B.L. et al. Fatores nutricionais que influenciam a qualidade do ovo no segundo ciclo de produção. I. Níveis de aminoácidos sulfurosos totais. Revista da Sociedade Brasileira de Zootecnia, v.25, n.2, p.248-260, 1996.

ROSTAGnO, H.S.; ALBINO, L.F.T.; DONZELE, J.L. et al. Tabelas brasileiras para aves e suínos: composição de alimentos e exigências nutricionais. 2.ed. Viçosa, MG: UFV, Departamento de Zootecnia, 2005. 186p.

SÁ, L.M.; GOMES, P.C.; ALBINO, L.F.T. et al. Exigência nutricional de metionina + cistina digestível para galinhas poedeiras no período de 34 a 50 semanas de idade. Revista Brasileira de Zootecnia, v.36, n.6, p.1837-1845, 2007.
SCHUTTE, J.B.; JONG, J.; BERTRAM, H.L. Requirements of the laying hen for sulfur amino acids. Poultry Science, v.73, p.274-280, 1994.

SNYDER, E.S. Eggs, the production, the identification and retention of quality in eggs. Guelp: Ontario Agricultural College, 1961. 90p.

TOGASHI, C.K.; FONSECA, J.B.; SOARES, R.T.R.N. et al. Determinação de níveis de metionina + cistina para poedeiras semipesadas alimentadas com rações contendo levedura seca (Saccharomyces cerevisiae). Revista Brasileira de Zootecnia, v.31, n.3, p.1426-1433, 2002.

UNIVERSIDADE FEDERAL DE VIÇOSA - UFV. SAEG - Sistema para análise estatística e genética. Versão 9.0 Viçosa, MG: UFV, 2005. 54p.

ZOLLITSCH, W.; ZHIQIANG, C.; PEGURI, A. et al. Nutrient requirements of laying hens. In: SIMPÓSIO INTERNACIONAL SOBRE EXIGÊNCIAS NUTRICIONAIS DE AVES E SUÍNOS, 1996, Viçosa, MG. Anais... Viçosa, MG, 1996. p.109-159. 